\title{
Is There a Fundamental Asymmetry among the Kinds of Objects in the Tractatus?
}

\author{
Andreas Georgallides \\ University of Cyprus, Nicosia, Cyprus \\ Email: ageorgallidis@yahoo.com
}

How to cite this paper: Georgallides, A. (2022). Is There a Fundamental Asymmetry among the Kinds of Objects in the Tractatus? Open Journal of Philosophy, 12, 123132.

https://doi.org/10.4236/ojpp.2022.121008

Received: November 30, 2021

Accepted: February 21, 2022

Published: February 24, 2022

Copyright $\odot 2022$ by author(s) and Scientific Research Publishing Inc. This work is licensed under the Creative Commons Attribution International License (CC BY 4.0).

http://creativecommons.org/licenses/by/4.0/ (c) (i) Open Access

\begin{abstract}
In this article, I examine whether the Tractarian objects include universals. I suggest that the Tractatus does not support a realist view-namely that apart from including particulars, objects also include universals-or a nominalist view - that is, that objects include only particulars. This is because, beyond the fact that there is no standard definition of the notions "particulars" and "universals", the term "object" remains indeterminate in the Tractatus. This contribution is important because it can encourage readers to think about why the nature of language and of the world is not clarified in the Tractatus something that creates the presuppositions for the necessity of a better consciousness for both language and the world.
\end{abstract}

\section{Keywords}

Tractatus, Particulars, Universals, Tractarian Object

\section{Introduction}

This article examines the question of whether there is a fundamental asymmetry between the different kinds of objects or expressions in the Tractatus. Stated in technical terms, the question can be formulated as follows: Do the Tractarian objects include universals? Traditionally, the discussion over this issue has fallen into two main views: 1) the nominalist view, by which objects only include particulars, which is to say, unique units; and 2) the realist view, according to which objects, apart from including particulars, also include universals, which is to say, properties and relations. A detailed presentation of these views, their implications and their validity lay beyond the scope of my article. Instead, I intend to illustrate how the indeterminacy of the notion, object, the notion (a linguistic device) upon which the terminological architecture of the Tractatus is based, does not allow for the possibility of elucidating this issue. This view is identified in 
Ramsey's suggestion that Wittgenstein deliberately remains neutral in the Tractatus, regarding the matter of whether he wishes to include universals in his notion of objects.

\section{Do Tractarian Objects Include Properties and Relations?}

From its opening remarks, the Tractatus does not provide any clarification as to whether there is a distinction between the kinds of objects in the world, in linguistic terms, with different kinds of names or between singular terms and some other kind of expression. Specifically, Wittgenstein writes: "The world is the totality of facts, not of things [Dinge]" (TLP 1.1, TLP indicates Pears and McGuinness' translation, see Wittgenstein, 2004). Since a fact is the existence of states of affairs (TLP2) and since Wittgenstein uses the German term "Dinge" ("things") in brackets in remark $T L P^{*} 2.01$ ( $T L P^{*}$ indicates Ogden's translation, see Wittgenstein, 2002) to explain the German term "Gegenstände" (“objects"), TLP 1.1 can be articulated as follows: the world is the totality of states of affairs, not of objects. This remark essentially asserts that the world is something more than the totality of objects. At the same time, however, Wittgenstein also claims that a state of affairs can be defined as a combination of objects (TLP 2.01). Based on remark $T L P 2.01$, the remark in $T L P 1.1$ can be reformulated as such: the world is the totality of the combinations of objects, not of objects.

When Wittgenstein articulates TLP 1.1, in a sense, he is exempted from the question of whether objects include properties and relations, thus leaving this issue open-ended. The Tractatus seems to imply that for an object to include properties and relations, it should be part of a state of affairs; that is, an object can include properties and relations only when it is combined (TLP2.03) with at least some other object ( TLP 2.0121). Therefore, taking TLP 1.1 into consideration, we can say that a state of affairs is not only a set of objects, but also a set of objects along with their properties and relations ${ }^{1}$, just as an elementary proposition is not only a set of names but also a set of names with their properties and relations $(T L P 3.141)^{2}$.

If we claim that there are objects that correspond to predicates (that is to say, names), this would mean that objects include particulars and universals; if not, this would mean that objects only include particulars. Hence, keeping in mind the non-specific nature of the identity of Tractarian objects, the crucial question arises as follows: how should a predicate be perceived in an elementary proposition? Since we cannot have an example of an elementary proposition, let us assume that "aRb" has the form of an elementary proposition, as it is preferable that a multiplicity (see TLP 4.04) applies to a symbolism that obeys the logical

${ }^{1}$ The same idea is expressed in Russell's Our Knowledge of the External World: “The existing world consists of many things with many qualities and relations. A complete description of the existing world would require not only a catalogue of the things, but also a mention of all their qualities and relations" (Russell, 1949: p. 60).

${ }^{2}$ In Letters to C.K. Ogden, Wittgenstein states that a proposition is "no MIXTURE at all but a STRUCTURE" (Wittgenstein, 1973: p. 24). Therefore, a structure can consist not only of its elements, but also of the relations of its elements. 
rules of grammar and not to an ordinary sentence (see TLP 3.325, 5.533, 5.534 and 6.122). Thus, considering "aRb", we can distinguish the following three cases.

(C1) If a predicate is understood to be an element of an elementary proposition, something which is not at all obvious in the Tractatus, then "aRb" consists of three elements: three names which relate to three objects, one of which is a predicate. In other words, it is comprised of two names ("a" and " $b$ ") and the name of a predicate ("xRy", where " $x$ " and " $y$ " are variables). This position is supported by remark TLP 2.01, according to which a state of affairs refers to nothing other than a combination of objects. In addition to this, in his comment to Ogden concerning $T L P^{\star} 2.03$ ("In the atomic fact [state of affairs] objects hang one in another, like the links of a chain"), Wittgenstein points out that: "Here instead of "hang one on another" it should be "hang one in another" as the links of a chain $d o$ ! The meaning is that there isn't anything third that connects the links but that the links themselves make connexion with one another" (Wittgenstein, 1973: p. 23) ${ }^{3}$.

From the above comment, Wittgenstein seems to imply that objects include relations. Also, in remark TLP 4.22, he asserts that an elementary proposition is only constituted by names, without any further discussion as to whether it needs something more. Moreover, Wittgenstein claims that:

(This shade of blue and that one stand, eo ipso, in the internal relation of lighter to darker. It is unthinkable that these two objects should not stand in this relation.)

(Here the shifting use of the word "object" corresponds to the shifting use of the words "property" and "relation"). (TLP4.123)

The second of the two claims above, keeping in mind the significance of use of the qualifier "shifting", supports the idea of a correspondence between the terms "property" and "relation" with the term "object".

Wittgenstein expresses the view that objects include relations and properties in the Notebooks of 1915, in which he makes the following statements:

Could one then manage without names? Surely not.

Names are necessary for an assertion that this thing possesses that property and so on (Wittgenstein, 1992: p. 53).

Relations and properties, etc. are objects too (Wittgenstein, 1992: p. 61) ${ }^{4}$.

A few days later he writes: "A name designating an object thereby stands in a relation to it which is wholly determined by the logical kind of the object and which signalises that logical kind" (Wittgenstein, 1992: p. 70). Consequently, by making reference to the "logical kind", Wittgenstein introduces the idea that not all objects belong to the same "logical kind"; in other words, he maintains that different objects belong to different logical kinds.

\footnotetext{
${ }^{3}$ Wittgenstein formulates this claim in the Notebooks as follows: "[the] connection is not a relation but only the holding of a relation" (Wittgenstein, 1992: p. 26).

${ }^{4}$ This idea is later expressed in Wittgenstein's Lectures Cambridge, 1930-32 as follows: “Objects' also include relations; a proposition is not two things connected by a relation. 'Thing' and 'relation' are on the same level. The objects hang as it were in a chain" (Wittgenstein, 1980: p. 120).
} 
Based on the idea expressed above (especially through the statements from the Tractatus), Wittgenstein seems to maintain that predicates are elements (names) of elementary propositions ${ }^{5}$. Therefore, if predicates are names, then relations are objects.

(C2) If "xRy" (where " $x$ " and " $y$ " are variables) is not understood to be an element of "aRb" that is to say, that it is a name which does not correspond to an element in the world, but rather concerns the way in which names are related, then "aRb" has two names: name "a" and name " $b$ ". The predicate does not function as a name and "xRy" is not related to a specific object. Wittgenstein expresses this view in his Notes on Logic, printed as Appendix I of Notebooks of 1913 as follows:

Indefinables are of two sorts: names, and forms ${ }^{6}$. Propositions cannot consist of names alone; they cannot be classes of names (Wittgenstein, 1992: p. 96).

Symbols are not what they seem to be. In "aRb", "R" looks like a substantive, but is not one. What symbolizes in " $a \mathrm{R} b$ " is that $\mathrm{R}$ occurs between $a$ and $b$. Hence " $\mathrm{R}$ " is not the indefinable in " $a \mathrm{R} b$ " (Wittgenstein, 1992: p. 98).

Moreover, in the Extracts from Wittgenstein's letters to Russell (1912-20), printed as Appendix III of Notebooks, Wittgenstein states:

[...] I have changed my views on "atomic" complexes: I now think that qualities, relations (like love) etc. are all copulae! That means I for instance analyse a subject-predicate proposition, say, "Socrates is human" into "Socrates" and "something is human", (which I think is not complex). The reason for this is a very fundamental one: I think that there cannot be different Types of things! In other words whatever can be symbolized by a simple proper name must belong to one type (Wittgenstein, 1992: pp. 121-122).

Although Wittgenstein does not express the above remarks in the Tractatus, he wrote them when he had also written a number of his remarks in the Notebooks, which later became part of the Tractatus. Thus, one could consider these to retain the same spirit as that of the Tractatus. It seems that predicates cannot be understood as elements of elementary propositions, but rather as forms of elementary propositions ${ }^{7}$. Therefore, objects do not include properties and relations ${ }^{8}$, and, perhaps, something beyond names is necessary to have complete elementary propositions.

(C3) According to Anscombe, it is possible that "aRb" contains names beyond those of " $a$ " and " $b$ ". Perhaps " $R$ " corresponds to a series of names; for instance, "c", "d" and "e" correspond to objects, since every state of affairs can be constituted by an infinite number of objects (TLP 4.2211) (Anscombe, 1996: p. 99). ${ }^{5}$ This view is mainly supported by Copi (1966), Ishiguro (1969), Carruthers (1989), Anscombe (1996), Ricketts (1996) and Fogelin (2004).

${ }^{6}$ This idea is reminiscent of Frege's distinction between complete and incomplete expressions. He uses the term "object" for the referents of "proper names" and the term "concept" for the referents of "predicates" (Frege, 1979: p. 17).

${ }^{7}$ This view is mainly supported by Stenius (1960), Allaire (1966), Hacker (1975), as well as Hintikka and Hintikka (1986).

${ }^{8}$ In his Notes Dictated to G. E. Moore in Norway, printed as Appendix II of Notebooks, Wittgenstein refers to the "difference between things, facts, properties, relations" (Wittgenstein, 1992: p. 109). 
Thus, "aRb" represents the proposition "acdeb" as a function of the two names, "a" and "b". Anscombe offers a non-linear picture" of an elementary proposition of the form "aRb" (Anscombe, 1966: p. 187) in the following way:

C

a d

e

Consequently, in order to have an isomorphism between that part of reality

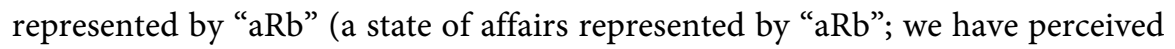
"aRb" to have the form of an elementary proposition) and its correspondent elementary proposition, that is to say "aRb" (see TLP 4.04), in the state of affairs, the elements must subsist as follows: according to the case (C1) three elementsobjects must subsist ${ }^{10}$ ("a", "b" and "xRy"; where " $\mathrm{x}$ " and " $y$ " are variables); according to the case (C2) two elements-objects must subsist ("a" and "b"); and according to case (C3), more than three elements-objects must subsist (depending on the names that are concealed in " $R$ ").

In the Tractatus, Wittgenstein seems to be indecisive about which of these three positions ( $\mathrm{C} 1, \mathrm{C} 2$ and $\mathrm{C} 3$ ) he should endorse. We do not know exactly how he understands predicates, as well as how he believes predicates to function within elementary propositions. In the Tractatus, he only mentions the term "predicate" once in remark TLP 4.1274, and without any further clarification. Additionally, he sometimes refers to the complex sign "aRb", without providing any further clarification of its elements (see TLP 3.1432, 4.012, 4.1252, 4.1273 and 5.5151). As a result, it is not clear how propositional elements can be combined in order to create a grammatical proposition.

\section{Ramsey Acknowledges Wittgenstein's Intention to Leave This Issue Open}

In his article entitled "Universals", Ramsey raises the question of whether "particulars" and "universals" are different kinds of objects. He contends that the "theory" of particulars and universals creates a "great muddle", which also leads him to the conclusion that among all philosophers, "Wittgenstein alone has seen through this muddle and declared that about the forms of atomic propositions we can know nothing whatever" (Ramsey, 1925: p. 417). He rightly believes that the theory of particulars and universals is problematic, since the view that "uni-

\footnotetext{
${ }^{9}$ Anscombe claims that singular propositions which are completely pictorial are non-linear and not of the form abcde. The crucial remark which Anscombe uses to support her view is TLP 3.1431. But in Wittgenstein's terms, the verb "imagine" makes the extract less specific. Beyond that, what is more confusing is that when Wittgenstein refers to complex objects, he uses the term "Gegenstände" (“objects").

${ }^{10}$ At this point, I follow Pears and McGuinness who translate the German terms "bestehend" and "bestehen" as "subsistent" (see TLP 2.0271) and "subsists", respectively (see TLP 2.024). This contrasts Ogden who renders the terms as "existent" and "exist", respectively (see $T L P^{\star}$ ). Although both terms are usually translated into English as "exist", they imply a major difference which Wittgenstein seems to emphasise when he refers to the existential character of objects. The term "bestehen", among others, states a relation of connection.
} 
versals are collections of particulars" and "particulars are collections of their qualities" provides little in the way of answers (Ramsey, 1925: p. 401). So, he denies the distinction between the logical roles of subjects and predicates ${ }^{11}$. More precisely, he mentions the following example: "Either Socrates is wise, or Plato is foolish". Indeed, in this proposition, it is possible to think of the term "Socrates" as the subject and "being wise unless Plato is foolish" as the predicate. Ramsey holds that it is completely wrong to think that the phrase "being wise unless Plato is foolish" should stand for a universal which would characterise Socrates. He does not adopt the idea that particulars are bound by the terms of the subject, while universals are bound by the terms of the predicate. Let us assume that we use "aRb", which we essentially think to be the form of an elementary proposition. The "theory" of particulars and universals would claim that there are three related propositions: (a) the relation " $R$ " stands between the terms " $a$ " and "b"; (b) the possession by "a" of the complex property " $R$ " to "b"; and (c) "b" has the property that "a" has " $R$ " to it. According to Ramsey, these three propositions, each with different sets of constituents, are not three different propositions, but rather only one, which can be read as follows: " $a$ " has " $R$ " to " $b$ " (Ramsey, 1925: pp. 405-406). Additionally, Ramsey states:

[...] it becomes clear that there is no sense in the words individual and quality [...] The two types being in every way symmetrically related, nothing can be meant by calling one type the type of individuals and the other that of qualities, and these two words are devoid of connotation.

To this, however, various objections might be made which must be briefly dealt with. First it might be said that the two terms of such an atomic fact [a state of affairs] must be connected by the characterising tie and/or the relation of characterisation, which are asymmetrical, and distinguish their relata into individuals and qualities. Against this I would say that the relation of characterisation is simply a verbal fiction. "q characterises a" means no more and no less than "a is q", it is merely a lengthened verbal form; and since the relation of characterisation is admittedly not a constituent of " $\mathrm{a}$ is q" it cannot be anything at all. As regards the tie, I cannot understand what sort of a thing it could be, and prefer Wittgenstein's view that in the atomic fact [state of affairs] the objects are connected together without the help of any mediator (Ramsey, 1925: p. 416).

\section{There Is Not a Standard Definition of "Particulars" and "Universals"}

Ramsey claims that the distinction between particulars and universals is not well defined and he admits that it is impossible to determine the basic structure of the world and of language. He assumes that we cannot know the form of an elementary proposition either a priori or a posteriori. This impedes us from know-

${ }^{11}$ Ramsey acknowledges that philosophers have been misled by the hypothesis that all propositions need to have the form subject-predicate (denying the existence of relations). He also believes that they have been misled concerning the question "what is merely a characteristic of language?" (Ramsey, 1925: p. 405). 
ing whether some or all objects can appear in more than one form of an elementary proposition as well as whether two objects can be constituted by terms of the same type. Therefore, according to Ramsey, since we cannot have knowledge about the form of elementary propositions, we cannot have knowledge about objects either ${ }^{12}$. Thus, a mathematical logician chooses to use types of objects which he refers to as "individuals" (Ramsey, 1925: p. 417). Hence, to be able to distinguish between different elements of the world-any possible world-(or between particulars and universals), we need to clarify (a) the categories on the basis of which elements are classified, and (b) the types of elements to which we refer.

While discussing the first point (a), we must acknowledge that there are no standard definitions for the notions of particulars and universals ${ }^{13}$. It is clearly difficult for commentators to give definitions and examples of the terms "particulars" and "universals". In many cases, it is implied that the available examples better contribute to the understanding of these terms, but I would suggest that this is, in fact, not the case. MacBride claims:

The concepts of particular and universal are introduced into philosophical discourse by way of a varied repertory of examples.

Persons, physical objects and events have served as paradigmatic examples of particulars. Attributes such as being human and being triangular, as well as spatial relations, have served as paradigmatic instances of universals (MacBride, 1998: p. 205).

These examples show that MacBride does not claim to be referring to "particulars" or "universals"; rather, he explains that these serve "as paradigmatic examples" or "as paradigmatic instances" of "particulars" and "universals", respectively. However, MacBride's examples are not particularly useful since they neither contribute to the elucidation of the definitions of these terms, nor do they indicate an effective way to develop a series of examples of them. At the same time, MacBride contends that "in general, an acceptable definition of the particular-universal distinction will, to a high degree, get the examples right" (MacBride, 1998: p. 206). Indeed, how is it possible to know whether we have chosen the right examples? First and foremost, this presupposes having a tremendous amount of knowledge about the nature of things in the world. Beyond that, however, the examination of isolated examples still does not allow us to formulate generalisations or definition-rules. The fact that the distinction between "particulars" and "universals" turns things towards the notion of instantiation, leaves the question open concerning what kinds of fundamental things there are.

While discussing the second point (b), namely, what type of elements we refer to, one would have to return to Ramsey who claims that a mathematical logician ${ }^{12}$ A year after publishing his article "Universals", Ramsey modified his view by stating that he was not sure that it is impossible to reach elementary propositions through analysis (Ramsey, 1994: p. 31).

${ }^{13}$ It is worth noting that "universals" should not necessarily be taken to be abstract, nor should "particulars" be taken as concrete. For instance, numbers are considered to be both concrete and abstract objects at the same time. Therefore, there are "particulars" which can be considered abstract. 
chooses to use one type of elements which he labels as "individuals" (Ramsey, 1925: p. 417). In a sense, the choice of a certain type of elements could be characterised as an arbitrary, yet legitimate and useful, procedure. This procedure, which depends on something we do with language, is arbitrary since it is very difficult to claim that the type of element we have chosen as a point of reference can cover and penetrate all things in the world. Even if we had succeeded in this, we would not be able to verify it. Consequently, every time we choose a different type of element, we most likely come to an extractive approach towards things in the world. It seems that this point is already quite clear to Wittgenstein who manages to imply precisely this in the lines of the Tractatus, leaving the identity of the term "object" unclear. Thus, he succeeds in retaining the appeal of his work without claiming that he is specifically classifying things in the world-or of any possible world-as this would require choosing either a specific type of objects or infinite types of objects. In another sense, the choice of a specific type of element could be considered legitimate and useful, given that the logician uses a specific type of element as a reference point in order to think about the distinctions between the kinds of things in the world. Of course, if we perceive Tractarian objects as reference points for the distinction between particulars and universals, then it is impossible to actually reach such a distinction. This is because the Tractatus does not tell us, nor does it allow us to figure out, what objects are. As Johnston says: "The Tractarian Wittgenstein does not merely avoid giving an answer to the question whether objects include universals: he rejects the terms of the question" (Johnston, 2009: p. 157) ${ }^{14}$.

\section{Concluding Remarks}

Clearly Wittgenstein rekindles the discussion about the fundamental asymmetry between the kinds of things of the world (in terms of language between different kinds of names) without maintaining a clear position as to whether the notion of objects should include properties and relations. Since it is impossible to know the form of an elementary proposition, as well as that of its objects, it is difficult to examine the logical terms of an elementary proposition based on the logical form of ordinary language. Since the forms of elements that result from analyses of ordinary sentences cannot possibly lead us to the form of objects of the complete logical analysis, there is no case in which we can reach a conclusion about the ontological nature of objects. The Tractatus only allows us to know some characteristics of objects and even then only in the context of a paradoxical work where the author encourages us to treat all of his remarks (which, as he contends, serve as elucidations) as nonsense (TLP 6.54). Consequently, we cannot

${ }^{14}$ Later, in Some Remarks on Logical Form $(R L F)$, Wittgenstein acknowledges that it is the task of the theory of knowledge to find elementary propositions, implying that this would be possible to achieve (Wittgenstein, 1966: p. 32). Additionally, he admits in Wittgenstein's Lectures Cambridge, 1932-35 that both he and Russell expected to find the "first elements", hence elementary propositions, through logical analysis. He also admits that it was a mistake to not give examples of elementary propositions since he maintains that elementary propositions are not the result of analysis, but are those which do not contain logical constants (Wittgenstein, 1979: p. 11). 
claim that the Tractatus encourages the idea of a fundamental asymmetry between the different kinds of objects in the world or of a fundamental asymmetry between the kinds of names, a distinction between singular terms and some other kind of expression. This can encourage us to think that the nature of language and the world have not yet been clarified. This attests to the need for a better consciousness for both language and the world.

\section{Conflicts of Interest}

The author declares no conflicts of interest regarding the publication of this paper.

\section{References}

Allaire, E. (1966). The Tractatus: Nominalistic or Realistic? In I. Copi, \& R. Beard (Eds.), Essays on Wittgenstein's Tractatus (pp. 325-341). Macmillan.

Anscombe, E. (1966). Mr. Copi on Objects, Properties, and Relations in the Tractatus. In I. Copi, \& R. Beard (Eds.), Essays on Wittgenstein's Tractatus (p. 187). Routledge and Kegan Paul.

Anscombe, E. (1996). An Introduction to Wittgenstein's Tractatus. Thoemmes Press.

Carruthers, P. (1989). Tractarian Semantics. Basil Blackwell.

Copi, I. (1966). Objects, Properties, and Relations in the Tractatus. In I. Copi, \& R. Beard (Eds.), Essays on Wittgenstein's Tractatus (pp. 167-186). Routledge and Kegan Paul.

Fogelin, R. (2004). Wittgenstein. Routledge.

Frege, G. (1979). Posthumous Writings. Basil Blackwell.

Hacker, P. (1975). Insight and Illusion. Oxford University Press.

Hintikka, M., \& Hintikka, J. (1986). Investigating Wittgenstein. Basil Blackwell.

Ishiguro, H. (1969). Use and Reference of Names. In P. Winch (Ed.), Studies in the Philosophy of Wittgenstein (pp. 20-50). Routledge and Kegan Paul.

Johnston, C. (2009). Tractarian Objects and Logical Categories. Synthese, 167, 145-161. https://doi.org/10.1007/s11229-008-9307-9

MacBride, F. (1998). Where Are Particulars and Universals? Dialectica, 52, 203-227. https://doi.org/10.1111/j.1746-8361.1998.tb00050.x

Ramsey, F. (1925). Universals. Mind, 34, 401-417. https://doi.org/10.1093/mind/XXXIV.136.401

Ramsey, F. (1994). Philosophical Papers (H. Mellor, Ed.). Cambridge University Press.

Ricketts, T. (1996). Pictures, Logic, and the Limits of Sense in Wittgenstein's Tractatus. In H. Sluga, \& D. Stern (Eds.), The Cambridge Companion to Wittgenstein (pp. 59-99). Cambridge University Press. https://doi.org/10.1017/CCOL0521460255.003

Russell, B. (1949). Our Knowledge of the External World. George Allen and Unwin.

Stenius, E. (1960). Wittgenstein's Tractatus. Basil Blackwell.

Wittgenstein, L. (1966). Some Remarks on Logical Form. In I. Copi, \& R. Beard (Eds.), Essays on Wittgenstein's Tractatus (pp. 31-37). Routledge and Kegan Paul.

Wittgenstein, L. (1973). Letters to C. K. Ogden (G. H. von Wright, Ed.). Blackwell.

Wittgenstein, L. (1979). Wittgenstein's Lectures Cambridge 1932-35 (A. Ambrose, Ed.). Basil Blackwell. 
Wittgenstein, L. (1980). Wittgenstein's Lectures Cambridge 1930-32 (D. Lee, Ed.). Blackwell.

Wittgenstein, L. (1992). Notebooks 1914-1916(G. H. von Wright \& E. Anscombe, Eds., \& E. Anscombe, Trans.). Basil Blackwell.

Wittgenstein, L. (2002). Tractatus Logico-Philosophicus (C. Ogden, Trans.). Routledge and Kegan Paul.

Wittgenstein, L. (2004). Tractatus Logico-Philosophicus (D. Pears \& B. McGuinness, Trans.). Routledge. 